\title{
Emergency Liquidity Provision to Public Banks: Rules versus Discretion
}

\author{
Achim Hauck* $\quad$ Uwe Vollmer ${ }^{\dagger}$
}

July 24, 2013

\begin{abstract}
This paper analyzes a government's incentives to provide financial assistance to a public bank which is hit by a liquidity shock. We show that discretionary decisions about emergency liquidity assistance result in either excessively small or excessively large liquidity injections in a wide variety of circumstances. Also, adding a lender of last resort does not generally ensure a socially optimal policy. However, optimal rules exist that align the preferences of the government and/or a lender of last resort with social preferences by either subsidizing or taxing liquidity aid.
\end{abstract}

JEL classification: G21, G28, L32

Keywords: Public banking, liquidity crises, lender of last resort, central bank, deposit insurance, forbearance.

\footnotetext{
*Corresponding author: Heinrich-Heine-University Düsseldorf, Department of Economics, Universitätsstraße 1, 40225 Düsseldorf, Germany, Tel.: +49/(0)211/81-15342, Fax.: +49/(0)211/81-12196, email: achim.hauck@uni-duesseldorf.de, and University of Portsmouth, United Kingdom.

${ }^{\dagger}$ University of Leipzig, Department of Economics, Grimmaische Straße 12, 04109 Leipzig, Germany, Tel.: +49/(0)341/97-33571, Fax: +49/(0)341/97-33579, email: vollmer@wifa.uni-leipzig.de.
} 


\section{Introduction}

In 1995, the average percentage of state ownership in the banking industry around the world was about 41.6 percent (La Porta et al, 2002). The subsequent trend towards privatization of public banks has been stopped by the recent worldwide financial crisis. In the course of the crisis, legislators in many countries introduced special bank restructuring and resolution schemes allowing governments to nationalize insolvent private banks. The aim was to prevent a sudden and disorderly collapse of systemically important financial institutions (SIFIs) with solvency problems, which were perceived as being "too big to fail" (Cihak and Nier, 2010). Accordingly, publicly owned banks still play an important role in the banking industry. ${ }^{1}$

When a public bank or a nationalized bank is hit by a major liquidity shock, crisis management is often a joint operation by multiple authorities. The government owning the bank can provide emergency liquidity in an attempt to keep the bank in operation. This distinguishes a public bank from private banks, whose owners are typically unable to provide or raise sufficiently large amounts of emergency liquidity at sufficiently short notice. In most countries, emergency liquidity assistance can also be provided by the national central bank, or occasionally by deposit insurers. ${ }^{2}$

These authorities pursue different goals and act under different constraints (Nakaso, 2001). A government may take budgetary measures but fear political opposition against the utilization of public funds. Central banks have the capacity to grant emergency loans,

$1 \quad$ Cases in point for systemically important financial institutions, which were nationalized during the financial crisis, are Hypo Real Estate and Commerzbank in Germany or the Belgian/French conglomerate Dexia, which was split up in 2011 into a Belgian and a French banking arm and resumed by the Belgian and French governments, respectively. Recent Data on the relevance of government owned banks can be found in the Worldbank Bank Regulation and Supervision Survey, which was completed in 2012, see http://go.worldbank.org/SNUSW978P0 and Barth et al (2012).

2 According to Barth et al (2006: 133) 69 out of 152 countries had an explicit deposit insurance scheme in $2002 / 2003$. 
but fear financial losses and risking their financial soundness. In most instances, they do not have to compensate losses of depositors as deposits are usually insured by the government or a (public or private) deposit insurance company.

Allowing multiple authorities with diverging mandates to decide about the provision of financial assistance may result in coordination failures. They may lead to delays in the rescue of failing banks or in socially suboptimal policies with the authorities providing too much (excessive forbearance) or too little (excessive intervention) financial assistance. ${ }^{3}$ To prevent coordination failures, central bank officials sometimes propose working out a specific loss sharing rule between the central bank and the government (Nakaso, 2001). However, to the best of our knowledge, such rules have not been implemented in any country, yet.

In this paper, we develop a theoretical model to investigate the implications of different regulatory frameworks for emergency liquidity provision to public banks or private banks which have been nationalized. Our analysis focuses on three aspects: First, we investigate the incentives of a government that owns a public bank to provide emergency liquidity in times of a crisis. We find that under discretion the behavior of the government will not be socially optimal unless it (i) faces no binding fiscal constraint, (ii) places the same weight on social bank failure costs as society does, and (iii) is solely responsible for guaranteeing deposits. ${ }^{4}$ Second, we discuss the implications of adding a lender of last resort (LLR) - the central bank or the deposit insurer - to the discretionary case. We find that the allocation

3 Barth et al. (2006: 57) report cases of apparently too generous public financial assistance. Recent examples for coordination problems resulting in delays in the provision of financial assistance are the cases of Glitnir Bank, the first Icelandic bank that collapsed in September 2008, and of Northern Rock which, on August 13, 2007, got into difficulties in renewing its short-term borrowings, see Benediktsdottir et al (2010, 2011), Hall (2008) and Shin (2009). On the case of Fortis, a BelgianDutch banking an insurance group which got into difficulties in September 2008, see Dewatripont et al. (2010).

4 Blume and Voigt (2013) and Tagkalakis (2013) are recent contributions that discuss limits on fiscal policy. 
of the LLR function will be relevant only if the deposit insurer has guaranteed at least some deposits of the public bank that is hit by the liquidity crisis. Then, the deposit insurer tends to be less willing to provide funds as LLR than the central bank as he fears potential costs of guaranteeing deposits in case of bank failure. Adding a LLR, however, does not generally enhance social welfare. Third, we show that optimal rules exist that align the agents' preferences with social preferences. Such optimal rules stipulate which agent decides on whether the public bank receives liquidity assistance and either force the LLR to subsidize (in case of too small liquidity injections) or tax (in case of too large liquidity injections) the provision of emergency liquidity to the public bank.

The paper adds to the growing literature on bank bailouts. The bulk of this literature rests on the assumption that a bank facing a liquidity crisis is forced into bankruptcy unless it obtains outside financial assistance. Accordingly, the results of this literature can only be applied to private banks with dispersed ownership which are unable to raise fresh inside liquidity at short notice. ${ }^{5}$ With its focus on the ex post incentives of the bank owner and a LLR to provide emergency liquidity, our paper is most closely related to Repullo (2000) and Kahn and Santos (2005, 2006). They concentrate on the ex post behavior of a LLR, after a liquidity crisis has emerged, and discuss whether the central bank or the deposit insurer should act as LLR or as bank supervisor when information about the solvency of banks is non-verifiable. They show that the optimal allocation of the LLR function depends on the extent of a bank's liquidity shortage and that in a multiregulator arrangement it is optimal to give supervisory power to the deposit insurer. In this paper, we extend the framework of Repullo (2000) and Kahn and Santos (2005, 2006)

$5 \quad$ Mitchell (1998), Corbett and Mitchel (2000), Diamond (2001), Osano (2002, 2005), Cordella and Yeyati (2003), Acharya and Yorulmazer (2008) and Dam and Koetter (2012) focus on the incentive effects of public bailouts on bank managers. Agion, Bolton and Fries (1999), Mitchell (2001), Tanaka and Hoggarth (2006), Wilson and Wu (2010), Dietrich and Hauck (2012), Bhattacharya and Nyborg (2013) and Wilson (2013) compare different policy measures to support distressed banks. 
by explicitly allowing for liquidity provision by bank owners when a liquidity crisis has occurred, which is plausible for public banks. Therefore, to the best of our knowledge, this paper is the first that analyzes the ex post incentives to provide support to a public bank facing a liquidity crisis.

As our focus is on the implications of a given regulatory framework for ex post emergency liquidity provision to distressed public banks, we abstract from scenarios in which the public authority owning a bank is able to alter regulations, e.g. by reallocating the LLR function, once a liquidity shock has occurred. This is reasonable if the public bank is owned by a regional or local authority which does not have the legislative power to make such legislative changes. Moreover, liquidity shocks require an immediate response to avoid a run of depositors making it difficult to alter the regulatory framework in time.

Also, our analysis abstracts from possible effects of different bank bailout and deposit insurance schemes on bank managers' ex ante risk taking incentives and depositors' ex ante monitoring incentives. Although there is no doubt on the relevance of these issues, turning them off sharpens our focus on the implications of the regulatory framework for ex post liquidity provision to distressed public banks. ${ }^{6}$ Throughout the paper we assume that all deposits are insured with a premium normalized to zero. However, we differentiate our analysis according to whether insurance is provided by the government, by an independent deposit insurance scheme (as in Switzerland or Germany), or jointly by both institutions.

The paper is organized as follows: Section 2 presents the model set-up and derives optimal financial assistance in the benchmark case with no informational asymmetries. Section 3 analyzes the government's incentives to provide emergency liquidity under dis-

$6 \quad$ The ex ante incentive effects of bank bailout schemes have already been discussed extensively in the literature, see the aforementioned references. For the ex ante incentive effects of deposit insurance schemes, see, e.g., Chan, Greenbaum and Thakor (1992) and Allen, Carletti and Leonello (2011). 
cretion with and without a LLR. Section 4 proposes a rule, which ensures optimal liquidity assistance. Section 5 concludes.

\section{Model Set-up and Benchmark Case}

We consider an economy with three agents at some date $t$ : a government and two regulatory authorities, the central bank and a deposit insurance agency. The government owns and runs a public bank which is hit by a liquidity shock. This shock will force the bank into liquidation unless it obtains sufficient emergency liquidity. The government is able to provide emergency liquidity to its bank. Also, the regulatory authorities are able to provide fresh liquidity. However, they may do so only if they have the right to serve as a LLR to the public bank.

At a previous date $t-1$, the public bank has invested EUR 1 in an indivisible, longterm project. The project is illiquid. It matures at date $t+1$. If the bank liquidates the project prematurely at the current date $t$, it will obtain only a small return $L \in(0,1)$. If the bank pursues the project until maturity, it will yield either a return $R>1$ (with probability $p$ ) or nothing at all. At $t-1$, the probability of success $p$ is a random variable. At the current date $t$, the government, which owns the public bank, privately observes the realization of $p$.

The public bank has financed its investment at date $t-1$ through deposits with face value $D=1$. The deposit insurance agency guarantees a share $\omega \in[0,1]$ of these deposits, the remaining share $1-\omega$ of deposits is guaranteed by the government. We assume that a stipulated sharing rule is always obeyed ex post. ${ }^{7}$ Depositors can withdraw their deposits

$7 \quad$ Japan before 1986 formed an example for a country with $\omega=0$. All deposits were guaranteed by the Ministry of Finance; the opposite case are the US where the government does not provide any deposit insurance. Many other countries are characterized by $\omega \in(0,1)$, deposits are co-insured by 
either early at $t$ or late at $t+1$. A publicly observable fraction $v \in(0,1)$ of deposits is withdrawn early at the current date $t$. As the public bank has no liquid funds at this date, $v$ can be viewed as a liquidity shock that hits the bank. If the government or a LLR provides a liquidity injection of $v$, the bank is able to repay early depositors without terminating the long-term project. Otherwise, the public bank must liquidate the project.

In this scenario, bankruptcy of the public bank can occur at date $t$ or at date $t+1$. At both points in time, bankruptcy of the public bank is associated with social costs $C$. As in Repullo (2000), these costs may comprise the administrative costs of closing the bank and paying back depositors as well as negative externalities of bankruptcy, like contagion to other banks or breakup of lending relationships. Bankruptcy will occur at $t$ if the bank does not receive liquidity assistance from the government or from the LLR, because the liquidation proceeds $L$ do not cover the claims of all depositors. Bankruptcy will occur at $t+1$ if the bank has obtained financial assistance at $t$ and the project fails at $t+1$. In this case, there are no funds available for paying out late depositors.

All agents in the economy are risk-neutral. Their preferences are represented by an additive-separable utility function defined over private profits and the social costs of bankruptcy. As the owner of the bank, the government cares about expected net profits of the bank, expected costs of guaranteeing the share $1-\omega$ of deposits, and the social bankruptcy $\operatorname{costs} C$. It weighs the latter by a factor $\alpha>0$. The two regulatory authorities, the central bank and the deposit insurer, are assumed to be independent from the government. Each regulatory authority weighs social bankruptcy costs by a factor $\beta>0$. In addition, it cares about expected losses (or profits) of providing support as LLR and, in case of the deposit insurer, about the expected costs of guaranteeing the share $\omega$ of

the government and deposit insurers. A case in point is Germany, where deposits are insured by the banking federation, but an unlimited state guarantee was announced in October 2008. 
deposits. The regulatory authorities supervise the bank. Hence, they find out the realization of the success probability $p$ at date $t$. This information, however, cannot be verified by the public. Finally, the amount $K^{G O V}$ that the government can inject into the public bank at $t$ in order to prevent bankruptcy is restricted to $K^{G O V} \leq K_{\max }^{G O V}$. This restriction, e. g., reflects the overall fiscal conditions, which may hamper the government's ability to provide fresh liquidity at short notice. Assuming $K_{\max }^{G O V} \geq(1-\omega)(1-L)$, the upper bound is large enough to ensure that the government credibly can guarantee a share $1-\omega$ of the claim $1-L$ of depositors if the public bank goes bankrupt at $t$ and is forced to liquidate its project.

Before analyzing the incentives of the government and a LLR to provide emergency liquidity to the public bank, it is useful to examine a first best world, in which the probability of success $p$ is publicly observable and verifiable. This case will serve as a benchmark for our later analysis. In a first best world, from the perspective of social welfare, it is optimal to provide liquidity assistance to the public bank at date $t$ whenever the expected returns less the social bankruptcy costs of continuing the project are (weakly) higher than the liquidation proceeds, net of $C$. Thus, the public bank should obtain sufficient liquidity at date $t$ if $p R-(1-p) C \geq L-C$. As in Repullo (2000), this leads to:

$$
p \geq \frac{L}{R+C}=: p^{f b} .
$$

Condition (1) states that in order to maximize social welfare, the bank should be closed if and only if the success probability of its long-term project is below a certain threshold $p^{f b}$. This threshold is higher, the higher is the liquidation value $L$ of the project and the lower are the potential long-term project returns $R$ and the bankruptcy costs $C$. Moreover, $p^{f b}$ 
does not depend on the magnitude $v$ of the liquidity shock at $t$. This is for two reasons. First, any provision of emergency liquidity leads to a pure redistribution of wealth from the liquidity provider to the public bank. Second, neither the potential liquidation proceeds nor the long-term project returns or the social bankruptcy costs depend on $v$.

\section{Provision of Emergency Liquidity under Discretion}

The success probability $p$ of the public bank's project is neither publicly observable nor verifiable. Therefore, it is impossible to directly implement the first best provision of emergency liquidity as specified in (1). However, one might aim to implement the first best indirectly. This might be achieved by a suitably designed regulatory framework. In this section, we concentrate on regulatory frameworks which allow agents to provide emergency liquidity in a discretionary way. We analyze three different scenarios. In the first, neither the central bank nor the deposit insurer is allowed to serve as a LLR so that only the government can prevent the public bank from going bankrupt at date $t$. In the second, the LLR function is allocated to the central bank. In the third, the deposit insurance agency may serve as a LLR instead of the central bank. We will see that all frameworks fail to implement a first best provision of emergency liquidity.

\subsection{No Lender of Last Resort}

If no regulatory authority may serve as LLR, the public bank will survive at date $t$ only if it receives support from the government. Accordingly, the bank will be forced into bankruptcy at this date whenever the liquidity shock $v$ exceeds the maximum amount

$K_{\max }^{G O V}$ that the government is able to provide. Otherwise, the government can choose between two options. It can either inject liquid funds $K^{G O V}=v \leq K_{\max }^{G O V}$ into the public 
bank. This prevents immediate bankruptcy. Alternatively, it can refuse to support the bank, so that the bank goes bankrupt at date $t$.

For a given liquidity shock $v$, the government will provide a liquidity injection $K^{G O V}=$ $v$ to prevent bankruptcy of the public bank at date $t$ only if it is able and willing to do so. This requires $v \leq K_{\max }^{G O V}$ and:

$$
-v+p[R-(1-v)]-(1-p)[(1-\omega)(1-v)+\alpha C] \geq-[(1-\omega)(1-L)+\alpha C] .
$$

The left-hand side of (2) reflects the government's expected payoff when providing sufficient emergency liquidity so that the public bank continues to exist until $t+1$. In this case, the government must inject the amount $v$ into the bank at date $t$. This amount is used to pay out early depositors. If the project of the public bank is successful at $t+1$, a return $R$ will materialize and late depositors receive $1-v$ from the bank. If the project fails, the bank cannot pay anything to late depositors. Due to the guarantee of deposits, the government then must settle a share $1-\omega$ of the total claim $1-v$ of late depositors. Moreover, the government must bear the weighted social bankruptcy costs. The right-hand side of (2) reflects the government's payoff when the bank is closed at date $t$. In this case, the liquidation proceeds $L<1$ are used entirely to repay depositors, the government must repay a share $1-\omega$ of the remaining deposits $1-L$, and the government suffers again from the social bankruptcy costs.

From the restriction $v \leq K_{\max }^{G O V}$ and from (2), we directly obtain: 
Lemma 1 If no LLR exists, the public bank will obtain sufficient emergency liquidity only if $p \geq \bar{p}$, where $\bar{p}$ is defined by:

$$
\bar{p}= \begin{cases}\frac{\omega v+(1-\omega) L}{R-\omega(1-v)+\alpha C} & \text { if } v \leq K_{\max }^{G O V}, \\ \infty & \text { if } v>K_{\max }^{G O V} .\end{cases}
$$

The lemma reveals that the government will provide emergency liquidity only if the liquidity shock $v$ of the public bank is sufficiently small and the probability of success $p$ is sufficiently large. The relevant threshold $K_{\max }^{G O V}$ for the liquidity shock simply reflects the maximum ability of the government to raise fresh funds at date $t$. If $v$ does not exceed this threshold, the relevant threshold $\bar{p}$ for the probability of success as defined in (3) depends on the fraction $\omega$ of deposits that is guaranteed by the deposit insurer. In this regard, it is useful to distinguish between two cases.

First, consider the case $\omega=0$, in which the government is solely responsible for guaranteeing deposits. For this case, (3) states that the threshold $\bar{p}$ does not depend on the magnitude of the liquidity shock. As the government guarantees all deposits, the timing of deposit withdrawals is irrelevant for its decision to rescue the public bank.

Second, consider the case $\omega>0$, in which the government shares the responsibility of guaranteeing deposits with the deposit insurer. In this case, the threshold $\bar{p}$ is higher, the higher is the magnitude $v$ of the liquidity shock, see (3). Accordingly, the government is the more reluctant to provide support to the bank, the higher is the shock. This is because the larger is the liquidity shock of the public bank at date $t$, the higher will be the costs of rescuing the bank, which are fully borne by the government, relative to the government's costs of guaranteeing a share $1-\omega$ of deposits in the event of insolvency of the public bank. 


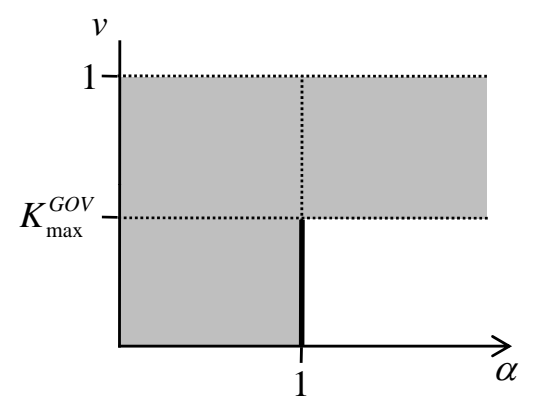

$\omega=0$

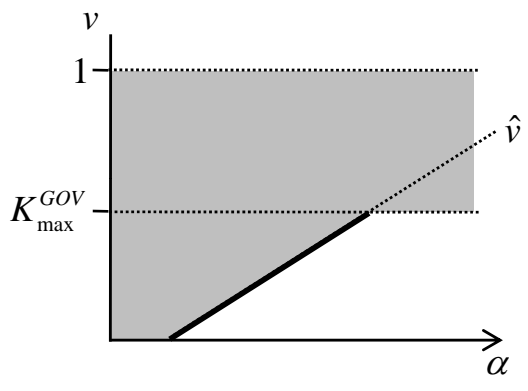

$\omega>0$

shaded area: too tough, non-shaded area: too soft, thickline: efficiency.

Figure 1: Liquidity Provision by the Government

By comparing $\bar{p}$ with the first best threshold $p^{f b}$ as defined in (1), we can conclude

Proposition 1 The threshold $\bar{p}$ has the following properties:

- For $\omega=0$ :

$$
\begin{array}{llll}
\bar{p}>p^{f b} & \text { if } \quad \alpha<1 \quad \text { or } & v>K_{\max }^{G O V}, \\
\bar{p}<p^{f b} & \text { if } \alpha>1 \text { and } & v \leq K_{\max }^{G O V}, \\
\bar{p}=p^{f b} & \text { if } \alpha=1 \text { and } & v \leq K_{\max }^{G O V} .
\end{array}
$$

- For $\omega>0$ :

$$
\begin{array}{llll}
\bar{p}>p^{f b} & \text { if } \quad v>\widehat{v} \quad \text { or } & v>K_{\max }^{G O V}, \\
\bar{p}<p^{f b} & \text { if } \quad v<\widehat{v} \quad \text { and } & v \leq K_{\max }^{G O V}, \\
\bar{p}=p^{f b} & \text { if } \quad v=\widehat{v} \quad \text { and } & v \leq K_{\max }^{G O V},
\end{array}
$$

where $\widehat{v}$ is defined by:

$$
\widehat{v}:=\frac{\omega(R+C-1)-(1-\alpha) C}{\omega(R+C-L)} L .
$$


Figure 1 illustrates the efficiency of government's actions in absence of a LLR for $\omega=0$ on the left hand side and for $\omega>0$ on the right hand side. It shows that first best behavior of the government will not be observed unless some rather specific prerequisites are met.

In case the government must fully guarantee deposits, $\omega=0$, the threshold $\bar{p}$ coincides with the first best threshold $p^{f b}$ only if $\alpha=1$ and $v \leq K_{\max }^{G O V}$, so that the government perfectly internalizes the social bankruptcy costs and is able to cope with the liquidity shock. For $\alpha<1$ or $v>K_{\max }^{G O V}, \bar{p}$ will be higher than $p^{f b}$. Then, the government is too tough. For any $p \in\left[p^{f b}, \bar{p}\right)$, it will not provide liquid funds to the bank, although this would be optimal from a first best perspective. This overly tough behavior stems from a too small weight that the government places on potential bankruptcy cost avoidance or from the government's inability to provide a sufficiently large liquidity injection. If $\alpha>1$ and $v \leq K_{m a x}^{G O V}$, it follows that $\bar{p}<p^{f b}$; the government will be too soft. It will provide liquidity assistance to the bank in some instances, although the bank would be closed in a first best world.

Matters are different when $\omega>0$, so that the government does not guarantee all deposits. Then, it will behave in line with the first best only if a liquidity shock $v=\widehat{v} \leq$ $K_{\max }^{G O V}$ emerges. For larger (smaller) shocks, the government will again be too tough (soft) relative to the first best.

\subsection{Central Bank as Lender of Last Resort}

Under what conditions will the public bank obtain sufficient emergency liquidity at date $t$ to prevent bankruptcy if we add the central bank as a LLR? To answer this question, we proceed in three steps. First, we determine the maximum amount of liquidity that the central bank is willing to inject into the public bank to prevent bankruptcy. Then, we 
determine the maximum amount that the government is willing and able to contribute. In the last step, we determine whether these amounts suffice to save the bank.

The central bank has not guaranteed deposits. It is not responsible for paying out depositors when the public bank goes bankrupt. Therefore, the central bank cares only about its potential costs of serving as a LLR to the public bank and about the weighted social bankruptcy costs. The central bank thus prefers to pay $K^{C B}$ for a rescue of the public bank over the bank's liquidation at date $t$ if:

$$
-K^{C B}-(1-p) \beta C \geq-\beta C,
$$

which can be rearranged to:

$$
K^{C B} \leq p \beta C=: \widehat{K}^{C B}
$$

Thus, the willingness to pay $\widehat{K}^{C B}$ of the central bank increases in the success probability $p$ of the public bank's project, the social bankruptcy costs $C$, and in the central bank's weight $\beta$ of these costs. Note that we treat $K^{C B}$ as a one-off payment from the central bank to the public bank that is not repaid. Alternatively, we could assume that the central bank provides a credit which must be repaid with a positive probability. Then, we could reinterpret $K^{C B}$ as the difference between the credit amount provided at date $t$ and the expected credit repayment at date $t+1$. This, however, would complicate the analysis without yielding much additional insight. 
The government's willingness to pay $\widehat{K}^{G O V}$ for a rescue of the public bank is relatively easy to derive. The government is ready to provide a liquidity injection $K^{G O V} \leq K_{\max }^{G O V}$ to prevent immediate liquidation of the public bank at date $t$ only if:

$$
\begin{aligned}
-K^{G O V} & +p[R-(1-v)]-(1-p)[(1-\omega)(1-v)+\alpha C] \\
& \geq-[(1-\omega)(1-L)+\alpha C]
\end{aligned}
$$

Note that (5) differs from the discretionary case (2) without a LLR in only one respect. Now, the government's liquidity injection $K^{G O V}$ must not necessarily coincide with $v$. Condition (5) can be rearranged to:

$$
K^{G O V} \leq(1-\omega)(v-L)+p[R-\omega(1-v)+\alpha C]=: \widehat{K}^{G O V} .
$$

As one would expect, $\widehat{K}^{G O V}$ decreases in the potential liquidation proceeds $L$ while it increases in the success probability $p$ of the project, its potential return $R$, and the social bankruptcy $\operatorname{costs} C$.

Based on the willingness to pay $\widehat{K}^{C B}$ of the central bank, the willingness to pay $\widehat{K}^{G O V}$ of the government and the upper bound $K_{\max }^{G O V}$, we can now assess whether or not the bank will obtain sufficient emergency liquidity at date $t$ to prevent bankruptcy. If the sum of $\widehat{K}^{C B}$ and $\min \left\{\widehat{K}^{G O V}, K_{\max }^{G O V}\right\}$ covers the liquidity shock $v$, the government and the LLR will agree to rescue the public bank, which then survives until $t+1$. If, however, $\widehat{K}^{C B}+\min \left\{\widehat{K}^{G O V}, K_{\max }^{G O V}\right\}$ falls short of $v$, no arrangement exists which is acceptable and feasible for both parties and prevents liquidation. Accordingly, we obtain: 
Lemma 2 If the central bank may serve as a LLR, the public bank will obtain sufficient emergency liquidity only if $\bar{p} \geq \bar{p}^{C B}:=\max \left\{\bar{p}_{u}^{C B}, \bar{p}_{r}^{C B}\right\}$, where $\bar{p}_{u}^{C B}$ and $\bar{p}_{r}^{C B}$ are defined by:

$$
\begin{aligned}
\bar{p}_{u}^{C B} & :=\frac{\omega v+(1-\omega) L}{R-\omega(1-v)+(\alpha+\beta) C}, \\
\bar{p}_{r}^{C B} & :=\frac{v-K_{\max }^{G O V}}{\beta C} .
\end{aligned}
$$

Allowing the central bank to serve as a LLR does not fundamentally alter the results. Still, the public bank will be bankrupt at date $t$ unless the probability of success $p$ of its project is high enough. The threshold $\bar{p}^{C B}$ will be equal to either $\bar{p}_{u}^{C B}$ or $\bar{p}_{r}^{C B}$. In the former case, the government is unrestricted. The maximum amount of liquidity $K_{\max }^{G O V}$ that the government can offer does not bind. In the latter case, $K_{\max }^{G O V}$ imposes a binding restriction on the government's liquidity provision.

The threshold $\bar{p}^{C B}$ will coincide with $\bar{p}_{u}^{C B}$ as long as the liquidity shock $v$ is relatively small. In this situation, the liquidity needs of the public bank are small relative to the willingness to pay of the LLR. As a consequence, $K_{\max }^{G O V}$ does not bind. That is, in case of $\bar{p}^{C B}=\bar{p}_{u}^{C B} \geq \bar{p}_{r}^{C B}$, the threshold for the probability of success is solely determined by the preferences of the LLR and the government. For large shocks, however, $K_{\max }^{G O V}$ does bind implying $\bar{p}^{C B}=\bar{p}_{r}^{C B}>\bar{p}_{u}^{C B}$. The restriction then forces the government and the central bank to let the public bank fail although in some situations they jointly would prefer to keep the bank in operation.

As long as $K_{\max }^{G O V}$ does not effectively restrict the government, allowing the central bank to serve as a LLR will alter the threshold $\bar{p}^{C B}$ relative to $\bar{p}$ in only one respect. This change stems from the weight $\beta$, which the central bank places on social bankruptcy costs 
and which will be internalized if the LLR function is allocated to the central bank. This internalization of the social bankruptcy costs suffered by the central bank unambiguously leads to a softer liquidity provision to the public bank, $\bar{p}_{u}^{C B}<\bar{p}$. However, the threshold $\bar{p}_{u}^{C B}$ will still depend positively on the magnitude $v$ of the liquidity shock unless the government provides a full guarantee of deposits, like in the case without a LLR. Also, the provision of emergency liquidity will still tend to be tougher, the lower is the joint weight $\alpha+\beta$ that the government and the central bank place on the social costs of bankruptcy of the public bank. If the restriction $K_{\max }^{G O V}$ binds, the positive effect of an increase in $v$ on the threshold $\bar{p}^{C B}=\bar{p}_{r}^{C B}$ will become larger. This is because any increase of the liquidity needs $v$ of the public bank must be satisfied by the central bank since the government cannot provide more liquidity than $K_{\max }^{G O V}$.

Concerning the efficiency implications of allowing the central bank to act as a LLR, we can conclude:

Proposition 2 The threshold $\bar{p}^{C B}$ has the following properties:

- For $\omega=0$ :

$$
\begin{aligned}
& \bar{p}^{C B}>p^{f b} \quad \text { if } \quad \alpha+\beta<1 \quad \text { or } \quad v>\widehat{v}^{C B}:=\widehat{v}_{r}^{C B}, \\
& \bar{p}^{C B}<p^{f b} \quad \text { if } \quad \alpha+\beta>1 \text { and } \quad v<\widehat{v}^{C B}:=\widehat{v}_{r}^{C B}, \\
& \bar{p}^{C B}=p^{f b} \quad \text { otherwise. }
\end{aligned}
$$

- For $\omega>0$ :

$$
\begin{aligned}
& \bar{p}^{C B}>p^{f b} \quad \text { if } \quad v>\widehat{v}^{C B}:=\min \left\{\widehat{v}_{u}^{C B}, \widehat{v}_{r}^{C B}\right\}, \\
& \bar{p}^{C B}<p^{f b} \text { if } \quad v<\widehat{v}^{C B}:=\min \left\{\widehat{v}_{u}^{C B}, \widehat{v}_{r}^{C B}\right\}, \\
& \bar{p}^{C B}=p^{f b} \quad \text { if } \quad v=\widehat{v}^{C B}:=\min \left\{\widehat{v}_{u}^{C B}, \widehat{v}_{r}^{C B}\right\},
\end{aligned}
$$



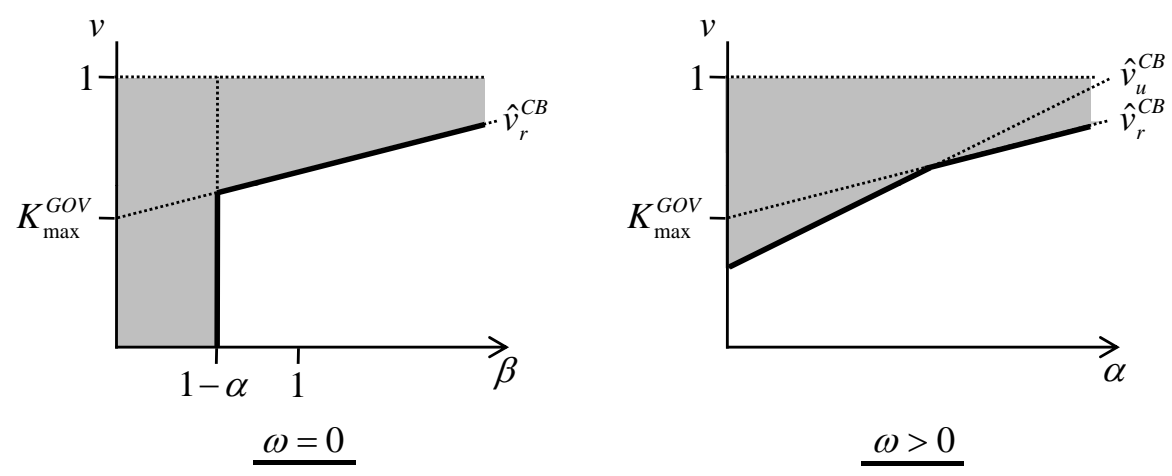

shaded area: too tough, non-shaded area: too soft, thickline: efficiency.

Figure 2: Liquidity Provision by Government and Central Bank

where $\widehat{v}_{u}^{C B}$ and $\widehat{v}_{r}^{C B}$ are defined by:

$$
\begin{aligned}
& \widehat{v}_{u}^{C B}:=\frac{\omega(R+C-1)-(1-\alpha-\beta) C}{\omega(R+C-L)} L, \\
& \widehat{v}_{r}^{C B}:=K_{\max }^{G O V}+\frac{\beta C}{R+C} L .
\end{aligned}
$$

The proposition shows that giving the central bank the right to provide liquidity as a LLR does not help to improve efficiency. A first best support of the public bank is still out of reach in most instances (see Figure 2). It will only be achieved in two situations. Either the government is unrestricted and must fully guarantee deposits while the sum of the weights $\alpha$ and $\beta$ is equal to one. Or the magnitude of the liquidity shock $v$ coincides with $\widehat{v}^{C B}$.

\subsection{Deposit Insurer as Lender of Last Resort}

When appointed as LLR, the deposit insurer will behave differently than the central bank, because unlike the central bank, the deposit insurer has guaranteed a share $\omega$ of deposits. 
Therefore, the deposit insurer is ready to pay $K^{D I}$ for rescuing the public bank at date $t$ only if:

$$
-K^{D I}-(1-p)[\omega(1-v)+\beta C] \geq-[\omega(1-L)+\beta C] .
$$

The left hand side of (6) reflects the expected payoff of the deposit insurer if the bank survives at date $t$. In this case, the insurer pays $K^{D I}$ to the bank at this date. If the bank's project succeeds at $t+1$, no further costs will accrue. If the project fails and yields no return, the deposit insurer must pay $\omega(1-v)$ to late depositors and will incur the bankruptcy costs. According to the right hand side of (6), liquidation of the public bank at date $t$ leads to a payment obligation $\omega(1-L)$ of the deposit insurer vis-a-vis those depositors, who receive nothing from the public bank, and to inevitable bankruptcy costs. Rearranging (6) leads to:

$$
K^{D I} \leq \omega(v-L)+p[\omega(1-v)+\beta C]=: \widehat{K}^{D I},
$$

where $\widehat{K}^{D I}$ denotes the maximum amount of liquidity that the deposit insurer is willing to provide. Interestingly, this maximum amount can be negative. This will happen whenever the liquidity shock $v$ is smaller than the potential proceeds of liquidating the public bank's project and the success probability of the project is rather small. In this case, the deposit insurer finds the potential avoidance of social bankruptcy costs less important than the long-term costs of guaranteeing deposits. Therefore, the deposit insurer would like to receive a compensation whenever the public bank is not closed at date $t$. We will return to this case of a possibly negative $\widehat{K}^{D I}$ shortly.

The government's incentives to provide emergency liquidity to the public bank at date $t$ do not depend on the allocation of the LLR function. Therefore, the government is 
still able and willing to rescue the bank as long as $K^{G O V} \leq K_{\max }^{G O V}$ and (5) is met. Its willingness to pay still satisfies:

$$
K^{G O V} \leq(1-\omega)(v-L)+p[R-\omega(1-v)+\alpha C]=: \widehat{K}^{G O V}
$$

We are now ready to clarify the conditions under which the government and the deposit insurer will rescue the public bank at date $t$ by providing sufficient emergency liquidity. If the deposit insurer's willingness to pay is non-negative, $\widehat{K}^{D I} \geq 0$, the relevant condition reads $\widehat{K}^{D I}+\min \left\{\widehat{K}^{G O V}, K_{\max }^{G O V}\right\} \geq v$. The public bank will survive as long as the joint willingness and ability to pay of the deposit insurer and the government covers the liquidity needs of the public bank. In case of a negative willingness to pay $\widehat{K}^{D I}$ of the deposit insurer, things are a bit more complex. If the LLR has the unilateral right to close the bank, the relevant condition will be $\min \left\{\widehat{K}^{G O V}, K_{\max }^{G O V}\right\} \geq v+\left|\widehat{K}^{D I}\right|$. This is because the government not only must pay at least $v$ to the public bank but it must also pay at least $\left|\widehat{K}^{D I}\right|$ to the deposit insurer since otherwise the deposit insurer would close the bank a $t$. If, however, the LLR has no unilateral right to close the bank, the relevant condition will be $\min \left\{\widehat{K}^{G O V}, K_{\max }^{G O V}\right\} \geq v$. In this case, the government can simply provide emergency liquidity to the public bank if it wishes to do so, and ignore the resulting loss of the deposit insurer. As this last case is essentially equivalent to the situation without any LLR, we assume that the LLR does indeed have the unilateral right to close the bank, so that we obtain: 
Lemma 3 If the deposit insurer may serve as a LLR, the public bank will obtain sufficient emergency liquidity only if $\bar{p} \geq \bar{p}^{D I}:=\max \left\{\bar{p}_{u}^{D I}, \bar{p}_{r}^{D I}\right\}$, where $\bar{p}_{u}^{D I}$ and $\bar{p}_{r}^{D I}$ are defined by:

$$
\begin{aligned}
\bar{p}_{u}^{D I} & :=\frac{L}{R+(\alpha+\beta) C}, \\
\bar{p}_{r}^{D I} & :=\frac{(1-\omega) v+\omega L-K_{\max }^{G O V}}{\omega(1-v)+\beta C} .
\end{aligned}
$$

If the government is unrestricted, the threshold $\bar{p}^{D I}=\bar{p}_{u}^{D I} \geq \bar{p}_{r}^{D I}$ will neither depend on the magnitude $v$ of the liquidity shock nor on how the government and the deposit insurer share the responsibility to guarantee deposits. Irrespective of $\omega$, these two parties are jointly responsible for fully guaranteeing deposits. Therefore, the share of early depositors is irrelevant for their decision to rescue the bank. If the restriction $K_{\max }^{G O V}$ binds, the relevant threshold reads $\bar{p}^{D I}=\bar{p}_{r}^{D I}>\bar{p}_{u}^{D I}$. Then, any increase in $v$ leads to an increase in the threshold since the associated higher liquidity needs of the public bank must be completely borne by the deposit insurer.

Interestingly, allowing the deposit insurer to act as LLR, who has the unilateral right to close the bank, will result in a tougher policy vis-a-vis the public bank whenever the bank's liquidity shock is relatively small. In this case, in which $\bar{p}^{D I}>\bar{p}$ holds true, the deposit insurer incurs an expected loss due to its obligation to guarantee deposits if the bank survives at date $t$ but fails at date $t+1$. Accordingly, the deposit insurer as a LLR agrees to a rescue of the bank only if he obtains a compensation from the government so that the latter tends to be tougher than in the case without a LLR.

From Lemma 3 and the first best threshold $p^{f b}$, we can infer: 

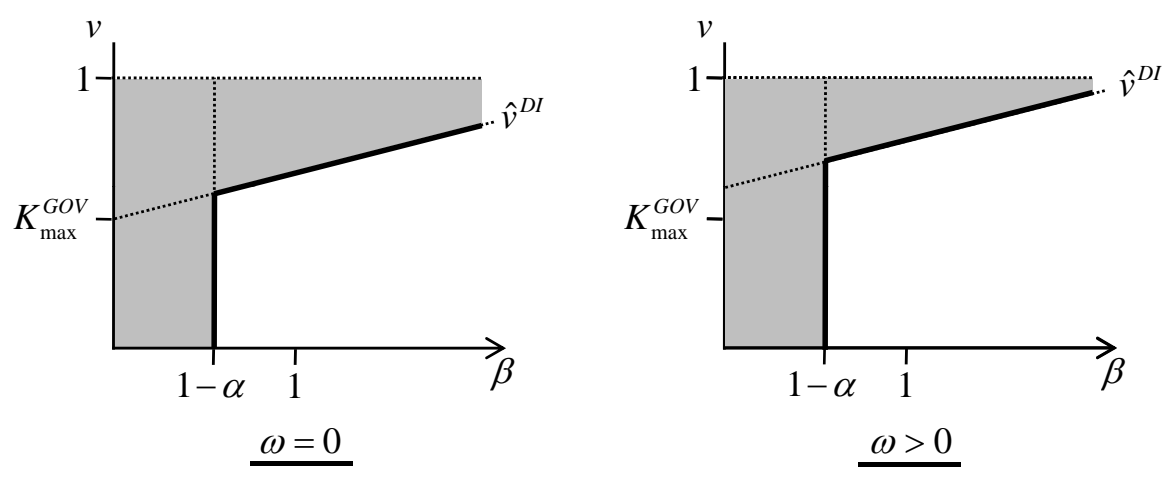

shaded area: too tough, non-shaded area: too soft, thickline: efficiency.

Figure 3: Liquidity Provision by Government and Deposit Insurer

Proposition 3 The threshold $\bar{p}^{D I}$ has the following properties:

$$
\begin{aligned}
& \bar{p}^{D I}>p^{f b} \quad \text { if } \quad \alpha+\beta<1 \text { or } \quad v>\widehat{v}^{D I}, \\
& \bar{p}^{D I}<p^{f b} \quad \text { if } \quad \alpha+\beta>1 \text { and } v<\widehat{v}^{D I}, \\
& \bar{p}^{D I}=p^{f b} \text { otherwise, }
\end{aligned}
$$

where $\widehat{v}^{D I}$ is defined by:

$$
\widehat{v}^{D I}:=\frac{[\beta C-\omega(R+C-1)] L+(R+C) K_{\max }^{G O V}}{(1-\omega)(R+C)+\omega L} .
$$

A graphical illustration of the efficiency implications of the deposit insurer serving as LLR is provided in Figure 3. The threshold $\bar{p}^{D I}$ coincides with the first best $p^{f b}$ under two circumstances. Either $\alpha+\beta=1$ holds and the shock $v$ is not too large. Then, the joint weight that the two parties place on social bankruptcy costs coincides with the social weight of these costs and the upper bound $K_{\max }^{G O V}$ for liquidity coming from the government is non binding. Or the sum of the weights exceeds 1 and the shock coincides with $\widehat{v}^{D I}$. Then, the restriction $K_{\max }^{G O V}$ on government's liquidity provision ensures first best behavior although the parties excessively internalize bankruptcy costs. For too large shocks $v$ or 
too little internalization of the costs of bankruptcy $(\alpha+\beta<1)$, the government and the LLR will be too tough, $\bar{p}^{D I}>p^{f b}$. Finally, overweighing the social cost $(\alpha+\beta>1)$ in conjunction with a sufficiently small shock will result in too soft behavior.

\section{Provision of Emergency Liquidity under a Rule}

In the preceding section, we have seen that discretion almost never leads to a first best provision of emergency financial assistance if the government as well as the central bank or the deposit insurer can act in a self-interested way. Of course, a government might wish to force the central bank or the deposit insurance to step in and to provide liquidity after the liquidity shock has occurred. Such commands are impossible, however, if the central bank or the deposit insurer are independent from the government, as is the case, e.g., in the European Monetary Union. Given independence of these institutions, it is natural to ask whether rules for the provision of emergency liquidity to the public bank can improve efficiency. In principle, a rule in our framework can stipulate (i) which agent may decide on whether the public bank obtains liquidity aid and (ii) the amount of liquidity that each agent involved in the rescue of the bank must provide.

This section investigates the implications of such a rule. In analogy to the previous analysis, we restrict attention to a rule involving two agents. The agent $i=G O V, C B, D I$ may decide whether the public bank is actually rescued at date $t$. If he decides to do so, he must inject the amount $K_{\text {rule }}^{i}$ into the bank. The remainder $K_{\text {rule }}^{L L R}=v-K_{\text {rule }}^{i}$ will then be provided by the agent $j=D I, C B, j \neq i$, who serves as LLR. Formally, this rule reads $\left\langle K_{\text {rule }}^{i} ; K_{\text {rule }}^{L L R}\right\rangle$ with $i=G O V, C B, D I$, where $i$ as well as $K_{\text {rule }}^{i}$ and $K_{\text {rule }}^{L L R}$ may depend on the magnitude of the public bank's liquidity shock $v$. 
Four remarks are useful to clarify the rule $\left\langle K_{\text {rule }}^{i} ; K_{\text {rule }}^{L L R}\right\rangle$. First, we do not place any restriction on $K_{\text {rule }}^{i}$. That is, a rule can, for example, stipulate $K_{r u l e}^{i}>v$, implying that $K_{\text {rule }}^{L L R}$ is negative. This can be interpreted as a tax that agent $i$ must pay when rescuing the bank. The rule can also stipulate $K_{\text {rule }}^{i}<0$, in which case agent $i$ will receive a premium from the LLR if he decides in favor of a rescue of the bank. Second, for the sake of simplicity, we treat $K_{\text {rule }}^{i}$ as well as $K_{\text {rule }}^{L L R}$ as a one-off payment from the respective agent to the bank (in case of $K_{\text {rule }}^{i}>0$ or $K_{\text {rule }}^{L L R}>0$ ) or vice versa (in case of $K_{\text {rule }}^{i}<0$ or $\left.K_{\text {rule }}^{L L R}<0\right)$ that is not repaid. Third, while $i$ as well as the respective payments $K_{\text {rule }}^{i}$ and $K_{\text {rule }}^{L L R}$ can be made contingent on the observable liquidity shock $v$, they cannot be made contingent on $p$ as the probability of success of the project is not verifiable. Fourth, the rule leaves no room for self interested discretionary behavior of the LLR. If agent $i$ decides to rescue the public bank, the LLR must pay $K_{\text {rule }}^{L L R}$ irrespective of whether he wishes to do so or not.

Let us start by investigating the rule $\left\langle K_{\text {rule }}^{G O V} ; K_{\text {rule }}^{L L R}\right\rangle$. This rule grants veto power to the government. The public bank will not receive liquidity aid unless the government prefers the aid over liquidation. The government is able and willing to rescue the bank if $K_{\text {rule }}^{G O V} \leq K_{\max }^{G O V}$ and

$$
-K_{\text {rule }}^{G O V}+p[R-(1-v)]-(1-p)[(1-\omega)(1-v)+\alpha C] \geq-[(1-\omega)(1-L)+\alpha C] .
$$

Like in (5), the left hand side of (7) reflects the government's expected return of providing support to the public bank at $t$ while the right hand side of (7) reflects the expected return of letting the bank go bankrupt. 
Under a second rule $\left\langle K_{\text {rule }}^{C B} ; K_{\text {rule }}^{L L R}\right\rangle$, the central bank is the veto player. It will opt for a rescue of the public bank only if its expected costs of rescuing the bank do not outweigh the costs of immediate bankruptcy. In analogy to (4), the formal condition reads:

$$
-K_{\text {rule }}^{C B}-(1-p) \beta C \geq-\beta C
$$

Similarly, a third rule $\left\langle K_{\text {rule }}^{D I} ; K_{\text {rule }}^{L L R}\right\rangle$ that lets the deposit insurer decide implies that the public bank survives the liquidity shock at date $t$ if:

$$
-K_{\text {rule }}^{D I}-(1-p)[\omega(1-v)+\beta C] \geq-[\omega(1-L)+\beta C] .
$$

The only difference between (8) and (9) stems from the fact that unlike the central bank, the deposit insurer is obliged to guarantee a share $\omega$ of deposits in case of bankruptcy of the public bank.

In conjunction with $K_{\text {rule }}^{G O V} \leq K_{\max }^{G O V}$, the respective conditions (7), (8) and (9) result in:

Lemma 4 Under a rule $\left\langle K_{\text {rule }}^{i} ; K_{\text {rule }}^{L L R}\right\rangle$ with $i=G O V, C B, D I$ and $K_{\text {rule }}^{L L R}=v-K_{\text {rule }}^{i}$, the public bank will obtain sufficient emergency liquidity only if $p \geq \bar{p}_{\text {rule }}$, where $\bar{p}_{\text {rule }}$ is defined by:

$$
\bar{p}_{\text {rule }}= \begin{cases}\infty & \text { if } i=G O V \quad \text { and } \quad K_{\text {rule }}^{G O V}>K_{\text {max }}^{G O V}, \\ \frac{K_{\text {rule }}^{G O V}-(1-\omega) v+(1-\omega) L}{R-\omega(1-v)+\alpha C} & \text { if } i=G O V \quad \text { and } \quad K_{\text {rule }}^{G O V} \leq K_{\text {max }}^{G O V}, \\ \frac{K_{\text {rule }}^{D I}-\omega v+\omega L}{\omega(1-v)+\beta C} & \text { if } i=D I, \\ \frac{K_{\text {rule }}^{C B}}{\beta C} & \text { if } i=C B .\end{cases}
$$


If the rule allows the government to decide about the public bank's rescue but includes a payment that the government cannot afford, the bank will be bankrupt at date $t$ irrespective of its liquidity shock $v$ and its future prospects. In all other cases, the distressed public bank will obtain sufficient liquidity assistance under a rule only if the probability of success of its project is sufficiently large. In this regard, the rule has similar implications as discretion.

Not surprisingly, the threshold $\bar{p}_{\text {rule }}$ depends positively on the amount $K_{\text {rule }}^{i}$ that agent $i$ must pay to rescue the bank for any given $v$. Moreover, the threshold depends negatively on the magnitude $v$ of the liquidity shock unless the central bank is the veto player. The higher is $v$, the less the public bank (and thus the government) must pay to late depositors at $t=1$, which increases the attractiveness of a rescue of the public bank (at given costs $K_{\text {rule }}^{G O V}$ ) from the government's point of view. For the deposit insurer, a similar argument applies. A higher $v$ will lower the costs of compensating late deposits if the bank is rescued at date $t$ but fails to generate a profit at $t+1$. For the central bank, the magnitude of the shock is irrelevant. This is because the central bank neither has a stake in the public bank's profits nor guarantees deposits so that it only trades off social bankruptcy costs, which are independent of $v$.

By setting $\bar{p}_{\text {rule }}$ equal to $p^{f b}$ and solving for $K_{\text {rule }}^{i}$, we can conclude:

Proposition 4 A first best outcome will be achieved under a rule $\left\langle K_{\text {rule }}^{i} ; K_{\text {rule }}^{L L R}\right\rangle$ with $i=G O V, C B, D I$ and $K_{\text {rule }}^{L L R}=v-K_{\text {rule }}^{i}$ if the rule has the following properties:

- For $\omega=0$ :

$$
K_{\text {rule }}^{i}=\left\{\begin{array}{lll}
v-(1-\alpha) \frac{C}{R+C} L & \text { if } i=G O V & \text { and } \quad K_{\text {rule }}^{G O V} \leq K_{\text {max }}^{G O V} \\
\frac{\beta C L}{R+C} & \text { if } i=C B & \text { or } \quad i=D I .
\end{array}\right.
$$


- For $\omega>0$ :

$$
K_{\text {rule }}^{i}= \begin{cases}v-\omega \frac{R+C-L}{R+C}\left(v-\widehat{v}_{\text {rule }}^{G O V}\right) & \text { if } i=G O V \quad \text { and } \quad K_{\text {rule }}^{G O V} \leq K_{\text {max }}^{G O V}, \\ \frac{\beta C L}{R+C} & \text { if } i=C B, \\ v-\frac{(1-\omega)(R+C)+\omega L}{R+C}\left(v-\widehat{v}_{\text {rule }}^{D I}\right) & \text { if } i=D I,\end{cases}
$$

where $\widehat{v}_{\text {rule }}^{G O V}$ and $\widehat{v}_{\text {rule }}^{D I}$ are defined by:

$$
\begin{gathered}
\widehat{v}_{\text {rule }}^{G O V}:=\frac{\omega(R+C-1)-(1-\alpha) C}{\omega(R+C-L)} L, \\
\widehat{v}_{\text {rule }}^{D I}:=\frac{\beta C-\omega(R+C-1)}{(1-\omega)(R+C)+\omega L} L .
\end{gathered}
$$

The proposition reveals that unlike discretion, a suitably designed rule will ensure that the liquidity provision for the public bank is consistent with the first best. However, to achieve efficiency, it may be necessary to exclude the government as the owner of the bank from the decision whether the bank receives aid and to allocate the power to decide to the central bank or the deposit insurer. This is due to the restriction $K_{\max }^{G O V}$ faced by the government, that limits the set of feasible rules.

In case of a non binding restriction $K_{\max }^{G O V}$ and $\omega=0$, in which the government is solely responsible for guaranteeing deposits, a rule with $i=G O V$ achieves a first best outcome by a money transfer $K_{\text {rule }}^{L L R}=v-K_{\text {rule }}^{G O V}=(1-\alpha) \frac{C}{R+C} L$, which does not depend on the liquidity shock $v$ of the public bank, see (10). Recall from Proposition 1 that under discretion, the government will be too tough if $\alpha<1$. The optimal rule then stipulates a payment from the LLR to the government, provided that the latter rescues the public bank. This payment makes the government softer. A first best policy is achieved. If, however, $\alpha>1$ holds true, the government tends to be too soft so that the optimal rule induces 
first best behavior by forcing the government to pay a fixed amount to the LLR when providing emergency liquidity to the public bank. Thus, in case of $\omega=0$, an optimal rule with $i=G O V$ will involve a subsidy if discretion is associated with too tough behavior, while it will involve a tax if discretion is associated with too soft behavior. Moreover, the subsidy or tax is independent of $v$ as the behavior of the government under discretion does not depend on $v$ either. This is due to the government's obligation to guarantee deposits fully.

The optimal rule with $i=G O V$ reaches its limits when the shock of the public bank becomes too large so that the optimal payment $K_{\text {rule }}^{G O V}$ of the government exceeds the upper limit $K_{\max }^{G O V}$. Then, it is useful to let either the central bank or the deposit insurer decide on the future of the public bank. Equation (10) reveals that as long as $\omega=0$, both options are equivalent. Since neither the central bank nor the deposit insurer must guarantee any deposits when $\omega=0$, their respective preferences are identical. Both options include a fixed payment of the respective agent $i$. This reflects the central bank's and deposit insurer's tendency to make its decision independently of $v$. As a consequence, a one-unit increase in $v$ will lead to a one-unit increase of the payment of the LLR under the optimal rule. Therefore, sufficiently small shocks are associated with a tax that agent $i$ must pay to the LLR while large shocks imply a subsidy for agent $i$.

The case $\omega>0$, in which some share of deposits is guaranteed by the deposit insurer, is similar to the case $\omega=0$. Again, an optimal rule with $i=G O V$ that induces first best behavior will exist as long as the liquidity shock of the public bank is not too large. However, (11) states the optimal rule will now depend on the realization of the liquidity shock $v$. If $v$ is relatively small, $v<\widehat{v}_{\text {rule }}^{G O V}$, the rule stipulates $K_{\text {rule }}^{L L R}=v-K_{\text {rule }}^{G O V}<0$, with $\frac{\partial K_{\text {rule }}^{L L R}}{\partial v}>0$. It thus punishes a rescue of the bank with a tax that decreases in the 
liquidity shock $v$ of the bank. This leads to a first best behavior as the government would be too soft under discretion with the degree of overly soft behavior being lower, the higher is $v$. For larger shocks $v>\widehat{v}$, the rule implies a subsidy $K_{\text {rule }}^{L L R}>0$, which increases in $v$, since under discretion the government tends to be tougher, the higher is the liquidity shock.

For too large shocks, the first best outcome will again be achieved only if either the central bank or the deposit insurer has veto power. In the former case, the optimal rule will (still) involve a payment of the central bank that is independent of the shock. In the latter case, the optimal payment of the deposit insurer will be higher, the higher is the shock. In either case, the rescue will again be taxed as long as $v$ is not too large and it will be subsidized otherwise.

Thus, a first best policy vis-a-vis the public bank can be achieved by a suitably designed rule, even though the realization of the success probabilities of the bank's project is not publicly observable. The optimal rule will depend on the observable magnitude $v$ of the liquidity shock of the public bank. If this shock is sufficiently low, the rule may allow the government, that owns the bank, to decide about the rescue of the bank. Otherwise, it must allocate the power to decide to the central bank or the deposit insurer. Moreover, the optimal rule will either force the LLR to subsidize a rescue (when agent $i$ tends to be too tough) or to tax it (when agent $i$ tends to be too soft).

\section{Summary}

The purpose of this paper was threefold: First, we have analyzed a government's incentive to provide financial assistance to a public bank which is subject to a liquidity shock. Second, we have analyzed the consequences of adding a LLR to the discretionary case. 
Third, we have discussed the implications of implementing a rule that stipulates how liquidity provision is shared between one agent that decides whether the bank receives help and the LLR.

We have shown that discretionary decisions by governments to provide financial assistance result in either excessively small or large liquidity injections in a wide variety of circumstances. Also, adding a LLR does not generally ensure a socially optimal policy. This is true irrespective of whether the LLR function is allocated to the central bank or the deposit insurer. However, a first best policy vis-a-vis the public bank can be achieved by a suitably designed rule, even though the realization of the success probabilities of the bank's project is not publicly observable. Depending on the magnitude of the public bank's emergency liquidity needs, the optimal rule allocates veto power to the government, the central bank or the deposit insurer. Besides, the optimal rule either subsidizes a rescue or taxes it.

This last point may be relevant also for the proper design of bank restructuring and resolution schemes which are currently introduced in several countries. These schemes enable national bank supervisors to nationalize SIFIs and either to resolve or to recapitalize them. For this purpose, restructuring funds are established by national governments which are often, as in the case of Germany, financed by a special bank levy, without any contribution by neither the deposit insurer nor the LLR (Deutsche Bundesbank, 2011). Our analysis suggests that a rule stipulating some burden-sharing between the bank restructuring scheme and either the deposit insurer or the LLR might be welfare-improving because it prevents the restructuring fund from being both too strict or too loose. 


\section{Acknowledgements}

The paper benefited from discussions with seminar participants at Hacettepe University, Ankara, Helmut-Schmidt-University, Hamburg, Radein-Seminar, and Kobe University. Instructive comments by Tobias Hiller and two anonymous referees as well as proofreading of an earlier version by Brian Bloch are particularly appreciated. Financial support by Fritz Thyssen Stiftung is gratefully acknowledged. Of course, the usual disclaimer applies.

\section{References}

Acharya, V., Yorulmazer, T., 2008. Cash-in-the-Market pricing and optimal resolution of bank failures. Review of Financial Studies 21, 2705-2742.

Aghion, P., Bolton, P., Fries, S., 1999. Optimal design of bank bailouts: The case of transition economies. Journal of Institutional and Theoretical Economics 155, 51-70.

Allen, F., Carletti, E, Leonello, A., 2011. Deposit insurance and risk taking. Oxford Review of Economic Policy 27, 464-478.

Barth, J. R., Caprio, G. Jr., Levine, R., 2006. Rethinking bank regulation. Till angels govern. Cambridge University Press, Cambridge, New York.

Barth, J. R., Caprio, G. Jr., Levine, R., 2012. The evolution and impact of bank regulations. World Bank Policy Research Working Paper, WPS6288, Washington.

Benediktsdottir, S., Gunnarsson, T., Hreinsson, P., 2010. Causes of the collapse of the Icelandic banks - responsibility, mistakes and negligence. Report prepared by the Icelandic Special Investigation Commission (SIC), 9 March 2009, http://www.rna.is/media/skjol/RNAvefurKafli21Enska.pdf.

Benediktsdottir, S., Danielsson, J., Zoega, G., 2011. Lessons from a collapse of a financial system. Economic Policy 26, 183-235. 
Bhattacharya, S., Nyborg, K. G., 2013. Bank bailout menus. Review of Corporate Finance Studies, Forthcoming.

Blume, L., Voigt, S., 2013. The economic effects of constitutional budget institutions, European Journal of Political Economy 29, 236-251.

Chan, Y.-S., Greenbaum, S. J., Thakor, A. V., 1992. Is fairly priced deposit insurance possible?. Journal of Finance 47, 227-245.

Cihak, M., Nier, E., 2010. The need for special resolution regimes for financial institutions

- The case of the European Union. IMF Working Paper, WP/09/200, Washington.

Cordella, T., Yeyati, E. L., 2003. Bank bailouts: Moral hazard versus value effect. Journal of Financial Intermediation 12, 300-330.

Corbett, J., Mitchell, J., 2000. Banking crises and bank rescues: The effect of reputation. Journal of Money, Credit and Banking 32, 474-512.

Dam, L., Koetter, M., 2012. Bank bailouts and moral hazard: Evidence from Germany. Review of Financial Studies 25, 2343-2380.

Deutsche Bundesbank, 2011. Fundamental features of the German bank restructuring act. Deutsche Bundesbank, Monthly Report 63 (June), 59-75.

Dewatripont, M., Rochet, J.-C., Tirole, J., 2010. Balancing banks. Global lessons from the financial crisis. Princeton University Press, Princeton, Oxford.

Dietrich, D., Hauck, A., 2012. Government interventions in banking crises: Effects of alternative schemes on bank lending and risk taking. Scottish Journal of Political Economy $59,133-161$.

Diamond, D., 2001. Should banks be recapitalized? Federal Reserve Bank of Richmond, Economic Quarterly 87, S. 71-96.

Hall, M. J. B., 2008. The sub-prime crisis, the credit squeeze and Northern Rock: The lessons to be learned. Journal of Financial Regulation and Compliance 16, 19-34. 
Kahn, C. M., Santos, J. A. C., 2005. Allocating bank regulatory powers: Lender of last resort, deposit insurance and supervision. European Economic Review 49, 2107-2136.

Kahn, C. M., Santos, J. A. C., 2006. Who should act as lender of last resort? An incomplete contracts model: A comment. Journal of Money, Credit and Banking 38, 1111-1118.

La Porta, R., Lopez-de-Silanes, F., Shleifer, A., Vishny, R., 2002. Government ownership of banks. Journal of Finance 57, 256-301.

Mitchell, J., 1998. Strategic creditor passivity, regulation and bank bailouts. CEPR Discussion Papers No. 1780, London.

Mitchell, J., 2001. Bad debts and the cleaning of banks' balance sheets: An application to transition economies. Journal of Financial Intermediation 10, 1-27.

Nakaso, H., 2001. The financial crisis in Japan during the 1990s: How the Bank of Japan responded and the lessons learnt. BIS Papers No 6, Basel.

Osano, H., 2002. Managerial compensation contract and bank bailout policy. Journal of Banking and Finance 26, 25-49.

Osano, H., 2005. An optimal scheme for injecting public funds under the moral hazard incentive for banks. Japanese Economic Review 56, 223-247.

Repullo, R., 2000. Who should act as lender of last resort? An incomplete contracts model. Journal of Money, Credit and Banking 32, 580-605.

Shin, H. S., 2009. Reflections on Northern Rock: The bank run that heralded the global financial crisis. Journal of Economic Perspectives 23, 101-119.

Tagkalakis, A., 2013, The effects of financial crisis on fiscal positions. European Journal of Political Economy 29, 197-213.

Tanaka, M., Hoggarth, G., 2006. Resolving banking crises - An analysis of policy options. Bank of England Working Paper No. 293, London. 
Wilson, L., 2013. Debt overhang and bank bailouts. International Journal of Monetary Economics and Finance, Forthcoming.

Wilson, L., Wu, Y., 2010: Common (stock) sense about risk-shifting and bank bailouts. Financial Markets and Portfolio Management 24, 3-29. 